\title{
Evaluation Method for Base Station Electromagnetic Radiation
}

\author{
Fengyu Lai \\ North China Electric Power University \\ Beijing, China \\ laifengyu316@163.com
}

\author{
Wenhua Ma \\ China Mobile Group Design Institute \\ Beijing, China \\ mawenhua@cmdi.chinamobile.com
}

\begin{abstract}
With the development of wireless communication technology, in order to meet the demand of network coverage and traffic capacity and so on, the number of base stations are growing, the electromagnetic radiation caused by base station becomes the focus of attention. The main content of this paper is about the base station electromagnetic radiation test evaluation. The purpose of this case study is to verify RF exposure compliance in publicly accessible areas for an indoor distributed antenna system, which is located in an office building. The paper uses the electromagnetic radiation tester NBM550 made in German to test. And the results of the tests are compared against the reference limits of National standard 8702-88 (GB 8702-88). Evaluation of uncertainty of this test method will be made. By this test, the author finds that the radiant quantities of base station are much smaller than the safety limit. In general case, electromagnetic radiation caused by base stations is no harm to human health.
\end{abstract}

Keywords-Electromagnetic radiation; standards; test; safety limit; uncertainty evaluation

\section{INTRODUCTION}

In recent years, the attention of electromagnetic radiation is always high, people are concerned about the impact of electromagnetic radiation to human body health. The process of electromagnetic radiation producing harm to human body is very complex, with a number of factors: The bigger the intensity of the radiation source is, the greater the electromagnetic pollution level is; the higher the frequency is, the greater the harm of electromagnetic radiation on biological is. In far-field region, the radiant intensity decreases with the increasement of the distance from the radiation source. The longer the radiation time is, the bigger the radiation hazard is, and so on. A large number of scientific experiments confirm that excessive electromagnetic radiation is harmful to human health ${ }^{[1][2]}$, but when the electromagnetic radiation level is in a narrow range, the electromagnetic radiation is safe and harmless to human body ${ }^{[3]}$.

With the development of the wireless communication technology, and the users' number increases rapidly, in order to meet the demand of network coverage and traffic capacity, especially in urban areas ${ }^{[4]}$, the mobile communication enterprises are building more and more communication base station, especially in urban areas, the distribution of base station is more and more intensive. A growing number of base station not only brought convenient communication, also increase the amount of radiation in the environment, and the electromagnetic radiation produced by base station becomes the focus of attention. And the electromagnetic radiation generated by mobile communication frequency mainly belongs to nonionizing radiation, its harm is smaller than ionizing radiation. But understanding the electromagnetic radiation of the mobile communication base station status and explore effective and convenient analysis and measuring method are also very necessary.

The electromagnetic radiation of mobile communication base station from three aspects, one is the electromagnetic leakage of a base station transmitter, the second is the joint electromagnetic leakage of the high frequency cable, the third is signal emission of transmitting antenna.

The purpose of this case study is to verify RF exposure compliance in public accessible areas for an indoor distributed antenna system, which is located in an office building. The antennas are mounted on the ceiling of each floor in an office build ing which houses a company for its adult staff. The results of the evaluations are compared against the reference limits of National standard 8702-88 of People's Republic of China (GB 8702-88).

\section{EVALUATION OVERVIEW}

\section{A. Electromagnetic Radiation Limit}

The intensity of the electromagnetic radiation of mobile communication base station is generally expressed by average power density. Based on human health, every country has the relevant documents to express provision the safety limit of the electromagnetic radiation intensity. Although different in specific provisions, most documents use basic limits and reference limits to express the electromagnetic radiation limit ${ }^{[5]}$.

Basic limits: The basic limit is to determine the body's basic amount of physiological responses to electromagnetic fields. The basic limit applies to the situation that the body is exposed to the environment. The basic limit of human exposure is usually expressed by Specific Absorption Rate which refers to electromagnetic radiation power absorbed by per biology unit mass, the absorbed dose rate.

Reference limits refer to the value that can produce . Reference limits are calculated based on the assumption of partial safety. Therefore, as long as the monitoring results are smaller than this value, almost can make sure the monitoring results don't exceed the basic limit of radiation protection. 


\section{B. Electromagnetic Radiation Standards}

There are two main standards in the world, one is "0 300GHz Electromagnetic safety limit Guideline", published by the International Commission for NonIonizing Radiation Protection in $1998^{[6][7]}$. The other one is by the Institute of Electrical and Electronic Engineers.

At present, the standard of the environmental protection departments of China is "Electromagnetic radiation protection regulations"(GB8702-88), which provides the electromagnetic radiation safety limit in our country is $40 \mu \mathrm{W} / \mathrm{cm}^{2}$. The reference standard of the test evaluation is "Electromagnetic radiation protection regulations". The electromagnetic radiation protection standards of China is much strict than abroad. Even when the environmental protection workers of China conduct an environmental impact assessment, the radiation standard is more strict. Because the general public total exposure dose include the sum of the influence of all kinds of electromagnetic radiation source, which does not only include the impact of proposed facilities may or has caused, but also includes the influence of the ambient fields' electromagnetic radiation. To make sure that the total exposure dose of the public is not greater than the limits of GB8702-88 prescribes, the impact on individual projects must be limited in one of several points of the limit according to local environment.

GB8702-88 prescribes include two cases, for general public and workers of exposure to the RF and microwave environment respectively ${ }^{[8]}$. GB8702-88 standard state that: 'exposure to the public is potentially 24 hours a day for 7 days a week, compared with 8 hours a day, 5 days a week for RF and microwave exposed workers'. The reference limits of occupational exposure and public exposure are listed in TABLE I and TABLE II respectively.

TABLE I. GB8702-88 REFERENCE LIMIT SFOR THE GENERAL PUBLIC

\begin{tabular}{|c|c|c|c|}
\hline $\begin{array}{c}\text { Frequency } \\
\text { (MHz) }\end{array}$ & $\begin{array}{c}\text { Eectric field } \\
\text { intensity } \\
(\mathbf{V} / \mathbf{m})\end{array}$ & $\begin{array}{c}\text { Magnetic field } \\
\text { intensity } \\
(\mathbf{A} / \mathbf{m})\end{array}$ & $\begin{array}{c}\text { Power density } \\
\left(\mathbf{W} / \mathbf{m}^{2}\right)\end{array}$ \\
\hline 0.1 to 3 & 40 & 0.1 & $40^{[1]}$ \\
\hline 3 to 30 & $67 / \sqrt{f}$ & $0.17 / \sqrt{f}$ & $12 / \mathrm{f}^{[1]}$ \\
\hline 30 to 3000 & $12^{[2]}$ & $0.032^{[2]}$ & 0.4 \\
\hline $\begin{array}{c}3000 \text { to } \\
15000\end{array}$ & $0.22 / \sqrt{f}$ [2] & $0.001 / \sqrt{f}$ & $\mathrm{f} / 7500$ \\
\hline $\begin{array}{c}15000 \text { to } \\
30000\end{array}$ & $27^{[2]}$ & $0.073^{[2]}$ & 2 \\
\hline $\begin{array}{c}\text { Not es: Averaging time of } 6 \text { minutes. } \\
\text { [1] An equivalent value of plane wave for reference. } \\
\text { [2] Value with rounding approximation and for reference only. }\end{array}$ \\
\hline
\end{tabular}

TABLE II. GB8702-88 REFERENCE LIMIT SFOR THE RF EXPOSED WORKERS

\begin{tabular}{|c|c|c|c|}
\hline $\begin{array}{c}\text { Frequency } \\
\text { (MHz) }\end{array}$ & $\begin{array}{c}\text { Electric field } \\
\text { intensity } \\
\text { (V/m) }\end{array}$ & $\begin{array}{c}\text { Magnetic field } \\
\text { intensity } \\
\text { (A/m) }\end{array}$ & $\begin{array}{c}\text { Power density } \\
\text { (W/m2) }\end{array}$ \\
\hline 0.1 to 3 & 87 & 0.25 & $20^{[1]}$ \\
\hline 3 to 30 & $150 / \sqrt{f}$ & $0.40 / \sqrt{f}$ & $60 / \mathrm{f}^{[1]}$ \\
\hline 30 to 3000 & $28^{[2]}$ & $0.075^{[2]}$ & 2 \\
\hline $\begin{array}{c}3000 \text { to } \\
15000\end{array}$ & $0.5 / \sqrt{f}[2]$ & $0.0015 / \sqrt{f}[2]$ & $\mathrm{f} / 1500$ \\
\hline $\begin{array}{c}15000 \text { to } \\
30000\end{array}$ & $61^{[2]}$ & $0.16^{[2]}$ & 10 \\
\hline $\begin{array}{c}\text { Not es: Averaging time of 6 minutes } \\
\text { [1] An equivalent value of plane wave for reference. } \\
\text { [2] Value with rounding approximation and for reference only. }\end{array}$ \\
\hline
\end{tabular}

\section{EVALUATION PLANNING}

\section{A. Selecting Test Site and Antenna}

The author chooses a four-layer office building, only TD-LTE Technology by China Mobile is available in this building.

During the measurement, five indoor distributed antennas in this building are chosen. All antennas are mounted on the ceiling of the floor and visible to the general public.

\section{B. Pre-evaluation Review}

The purpose of the pre-evaluation review is to develop an estimate of the expected field strength and consequently select appropriate evaluation methods for a given evaluation purpose. The indoor distributed antenna is mounted on the ceiling. No radiated source exists in the scope of the line-of-sight. In this case, ambient fields need not be evaluated. The power density value is determined for each measurement locations, and the expanded uncertainty of measurement is analyzed too.

The size of electromagnetic radiation is not only related to the distance, but also related to other factors such as telephone traffic ${ }^{[9]}$. This case study focuses on distance factor.

\section{Test Steps}

- On each test point, ensure the probe occupy the expected position and the usage of tester is correct.

- Then, take measurement for a total of 30 seconds, and read the maximu mumber of a stable state. If the measurements is not stable, the time of measurement needs to be extended. Every point needs to be tested five times.

- Record the data.

- Repeat the step 1 to 3, implement for every test point. Every antenna should choose 11 test points, as shown in Fig.1, and the test points are A to K. 


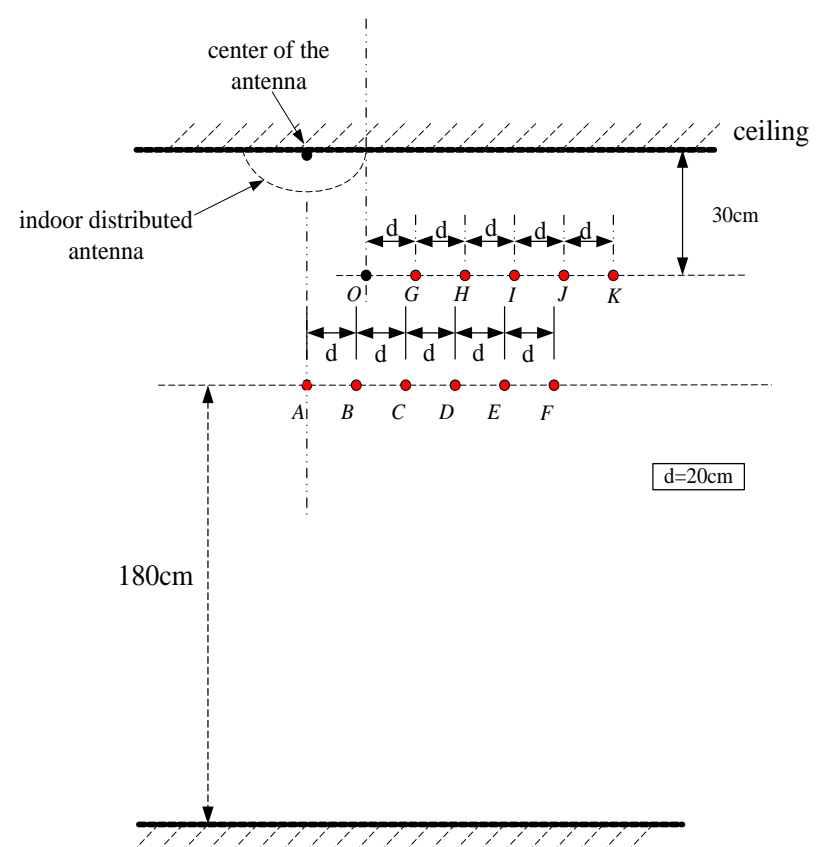

ground

Figure 1. Testing points for on-site measurement.

\section{THE RESULT OF TEST}

\section{A. Test Data}

The paper tests the power density of all test points of each antenna. The unit of power density is $\mu \mathrm{W} / \mathrm{cm}^{2}$. All of the data refers to the average of the test data, as shown in TABLE III. A to $\mathrm{K}$ are the test points, 1 to 5 are antenna numbers.

TABLE III. AVERAGE OF TEST DAT A

\begin{tabular}{|c|c|c|c|c|c|}
\hline \multirow{2}{*}{} & \multicolumn{5}{|c|}{ Power density ( $\boldsymbol{\mu W} / \mathbf{c m} 2)$} \\
\cline { 2 - 6 } & Antenna 1 & Antenna 2 & Antenna 3 & Antenna 4 & Antenna 5 \\
\hline A & 0.20 & 0.26 & 0.34 & 0.10 & 0.10 \\
\hline B & $<0.10$ & 0.20 & 0.14 & $<0.10$ & $<0.10$ \\
\hline C & 0.10 & 0.20 & 0.38 & 0.30 & $<0.10$ \\
\hline D & 0.25 & 0.32 & 0.20 & 0.20 & 0.20 \\
\hline E & 0.20 & 0.36 & 0.10 & 0.12 & 0.22 \\
\hline F & 0.35 & 0.52 & 0.22 & 0.10 & 0.30 \\
\hline G & 0.40 & 0.72 & 0.45 & 0.64 & 0.48 \\
\hline H & 0.64 & 0.70 & 0.42 & 0.80 & 0.42 \\
\hline I & 0.58 & 0.58 & 0.20 & 0.76 & 0.40 \\
\hline J & 0.40 & 0.44 & 0.30 & 0.58 & 0.52 \\
\hline K & 0.35 & 0.40 & 0.24 & 0.42 & 0.30 \\
\hline
\end{tabular}

\section{B. Evaluation of Uncertainty}

1) Type A uncertainty evaluation method: Evaluation of uncertainty caused by the instability of transmitting power.

During the measurement, test standard method requires the same test point which needs to be tested for 5 times within the setting time, then take the arithmetic mean value of the five data as test results. For class this type uncertainty evaluation, every test point needs to be tested for 10 times continuously, and calculate arithmetic mean value and experimental standard deviation, then calculate the uncertainty of this evaluation standard according to Bessel formula.

$$
u_{A}\left(x_{i}\right)=\frac{s\left(x_{i}\right)}{\sqrt{n}}=\frac{s\left(x_{i}\right)}{\sqrt{n}}, \mathrm{n} \text { for test times. } 1
$$

2) Type $B$ uncertainty evaluation method: Evaluation of uncertainty caused by tester system error.

According to the probe technical indicators:

Flatness of frequency response: $\pm 1 \mathrm{~dB}(1 \mathrm{MHz}$

$1 \mathrm{GHz}), \pm 1.25 \mathrm{~dB}(1 \mathrm{GHz} 2.45 \mathrm{GHz})$

Calibration uncertainty: $\pm 0.75 \mathrm{~dB}$;

Linearity: $\pm 0.5 \mathrm{~dB}(1.2 \sim 200 \mathrm{~V} / \mathrm{m}), \pm 0.7 \mathrm{~dB}(200 \sim$ $320 \mathrm{~V} / \mathrm{m})$;

Is otropic response: $\pm 1 \mathrm{~dB}$.

The standard uncertainty caused by the tester probe is $0.8 \mathrm{~dB}$.

3) Evaluation of combined standard uncertainty

Combined standard uncertainty is calculated by type A uncertainty and type B uncertainty:

$$
u_{c}=\sqrt{u_{A}^{2}\left(\bar{x}_{i}\right)+u_{B}^{2}\left(x_{i}\right)}
$$

\section{4) Evaluation of expanded uncertainty}

Take the confidence level as $95 \%$, coverage factor $\mathrm{k}=2$, expanded uncertainty:

$$
U=k \cdot u_{c}=2 \times u_{c}
$$

\section{CONCLUSIONS}

The maximum value of the data is $0.80 \mu \mathrm{W} / \mathrm{cm}^{2}$ with expanded uncertainty at the test point $G$ of antenna 2 , which is much less than the safety limit $40 \mu \mathrm{W} / \mathrm{cm}^{2}$ of GB8702-88 for public. As the height of measurement location is $2.0 \mathrm{~m}$ from the floor ground, the space above the measurement location is not accessible to the general public. Therefore, the radiant quantity of this building's base stations is in compliance with National standard 8702-88 (GB 8702-88).

According to the relevant provisions of the environment protection department ${ }^{[10]}$, before the construction of base stations, the environmental impact assessment must be carried on. In operation stage after the construction of base stations, it also should be tested and evaluated by the environmental protection department at regular intervals. Electromagnetic radiation caused by base stations is no harm to human health in general case.

\section{ACKNOWLEDGMENTS}

All the received signals are procssed by the software "SmartSignalProcessing" developed by Prof. Ming-Yue Zhai at North China Electric Power University.

\section{REFERENCES}

[1] Xie Yinyue. Analysis about the impact of mobile communication base station electromagnetic radiation to the environment[J]. Mobile Communication, 2011.

[2] Osman Çerezci, Baha Kanberoğlu, Şuayb Çă̆rı Yener. Analysis on trending electromagnetic exposure levels at homes and proximity next to base stations along three years in a city[J]. Journal of Environmental Engineering and Landscape Management,2015,231:.

[3] Lin, J.C., "Safety standards for human exposure to radio frequency radiation and their biological rationale," Microwave Magazine, IEEE, vol.4, no.4,pp.22,26, Dec. 2003 
[4] Calin, M.D.; Ursachi, C.; Helerea, E., "Electromagnetic environment characteristics in an urban area," Electrical and Electronics Engineering (ISEEE), 2013 4th International Symposium on , vol., no., pp.1,6, 11-13 Oct. 2013

[5] Ma Wenhua. Electromagnetic radiation standard tracking study[J]. Telecom Engineering Technics and St andardization,2007,01:30-32.

[6] Kang Ning. Research of mobile communication base station electromagnetic radiation[D]. Beijing University of Posts and Telecommunication, 2011.

[7] Homeopathy, S.; Sanyal, A., "A review of the effects of nonionizing electromagnetic radiation on human body and exposure standards," Electromagnetic Interference and Compatibility 97.
Proceedings of the International Conference on, vol., no., pp.279,288, 3-5 Dec 1997

[8] Lin, J.C., "Safety standards for human exposure to radio frequency radiation and their biological rationale," Microwave Magazine, IEEE, vol.4, no.4,pp.22,26, Dec. 2003

[9] Lv Jianhong, Peng Jiwen, Fang Fang, Yang Zuqiang, Zhou Haihua. Mobile Communication Base Station Antenna Electromagnetic Radiation Distribution Law and Research of Safety Protection[J]. Environment Science and Technology,2013,07:201-205.

[10] Method of Electromagnetic Radiation Monitoring for Mobile Communication Base Station[S]. (in Chinese) 